\title{
Physical Education Teaching in Colleges and Universities in the Concept of Health Quotient Research Situation and Development Strategy \\ Jian-qiang GUO ${ }^{1,{ }^{*}}$, Wen-jie $\mathrm{ZHU}^{2}$ and Qin-er $\mathrm{XU}^{1}$ \\ ${ }^{1}$ Changzhou University sports institute \\ ${ }^{2}$ Suzhou Art and Design Technology Institute, Jiangsu Suzhou, China \\ *jqguo5986@163.com
}

Keywords: Health quotient concept, College sports, The teaching status quo, The development strategy.

\begin{abstract}
In this paper, through the concept of health quotient in colleges and universities sports teaching present situation research, find the university sports education existence weak link, for physical education teaching in colleges and universities to provide constructive development strategies and Suggestions, this paper focuses on health quotient concept under the situation of college physical education and strengthen strategies.
\end{abstract}

\section{The Current PE Teaching Situation Based on Health Quotient Concept}

College physical education is undoubtedly an important carrier and the main position of health quotient education of college physical education, but because the long-term ignorance for health quotient concept leads to the current situation of university sports health teaching not very optimistic, the HQ index of college students are mostly in the middle and lower levels. Specifically, the main expression can be seen in the following points:

Ignore the Main Body of Students in Sports Class and do not Attach Importance to the Cultivation of Individual Quality

The expansion policy has provided the opportunity to receive higher education to more people, but also brought some problems to the current university sports education. Because there are too many students, so the teaching mode is to teach in a large class basically, formulate a unified syllabus and teaching plan, one-way, unified teaching to the student and failed to fully ensure the subject status of students in PE class, so that only the development of the students' common quality can be carried out. It is disadvantageous for the cultivation of students' personal qualities. For example, in class teaching mode, students' interest and enthusiasm for learning is often difficult to be stimulated. And unified teaching mode is unable to meet the needs of different students' interest and learning needs, which restricts the improvement of teaching quality.

\section{The University Sports Teaching System and Curriculum Is Not So Scientific}

In college physical education teaching, textbook is an important basis for teaching activities and also an important channel for students to acquire knowledge and skills, so the setting of curriculum construction and teaching material system of college sports determine the direction and quality of PE teaching to a certain extent. However, in the current teaching system, there lies a problem that the guidance is not strong and health quotient content rarely involved, which has become an important cause of 
improving ability to influence health quotient of college students. Looking from whole, the current PE theory teaching material available is mainly about the method of physical training, sports health, sports safety and the content of enhancing physical fitness. Sports ethics, sports interest cultivation, mental disorder, mental health and other related with the health quotient concept is relatively too little so that the guidance and scientific of existing materials the applicability of the system have a greatly discount. In addition, in the teaching practice of sports, class theory course is relatively very limited, usually only about $15 \%$ 20\%, but mainly to the students' self-study. Practice course can account for the proportion of $80 \% \sim 85 \%$, but also exists certain irrationality in the teaching arrangements, such as the time arrangement less or arrangement in the first class after lunch. And it is only opened for Grade1 and Grade2 and this is obviously not conducive to cultivate students' consciousness of lifelong sports.

\section{Defects in the Teaching Evaluation System}

Teaching evaluation purposes, on the one hand, is to do the student learning outcomes assessment and promotes the development of students, on the other hand is to evaluate the teachers' teaching activities, promote the change of teaching mode and improvement of teaching quality. But in the concrete teaching practice, there are a lot of "exam oriented" phenomenons. Some students do not want to take PE lesson. They learn what will be examined by the teacher and even shout "long live 60 points". On the one hand, it highlights the disadvantages of college physical education teaching evaluation, on the other hand, it is an important manifestation of the lack of students' health quotient concept. Positive changes in physical education, from the consequential assessment and skills single evaluation to process and comprehensive evaluation are urgently needed as soon as possible. We should protect the students' initiative and enthusiasm in PE class and increase the sports awareness, participation, cooperative spirit and health quotient education evaluation criteria.

\section{The lack of Health Education}

In the current sports practice in college teaching, teaching content is mainly in the form of competitive sports items and sports health education has not drawn enough attention. This runs counter to the current sports teaching concept "physical education and health first". Many universities teaching goal is confined to enhance the students physical skills. Most sports content selection is competitive sports and the evaluation method is to motivate the students to improve the competitive ability. but it ignores the osmosis in the teaching practice of the health quotient concept such as students' health education and sports spirit, which is not conducive to the cultivation of the students' good sports behavior.

\section{Strategy Research of College PE Teaching Based on Health Quotient Concept}

Physical education as an important part in higher education, under the background of "national fitness", "health first" and "Sunshine Sports", the aim of education is to by passing on the sports knowledge, sports skills and basic skills, enhance the physical quality of the students, regulate the physiological state of the students, let students form a good the habit of lifelong exercise and maintain a healthy body in each age stage and ensure that the quality of learning, life and work.

Health quotient as a kind of brand-new healthy idea, is an important way to promote the health of students. Therefore, in college PE teaching practice, we should attach importance to the guidance of health quotient concept, actively explore more effective 
teaching strategies and better achieve the goal of college sport teaching. As is shown in Picture 1, it is the design of the use of health quotient concept in college sports teaching.

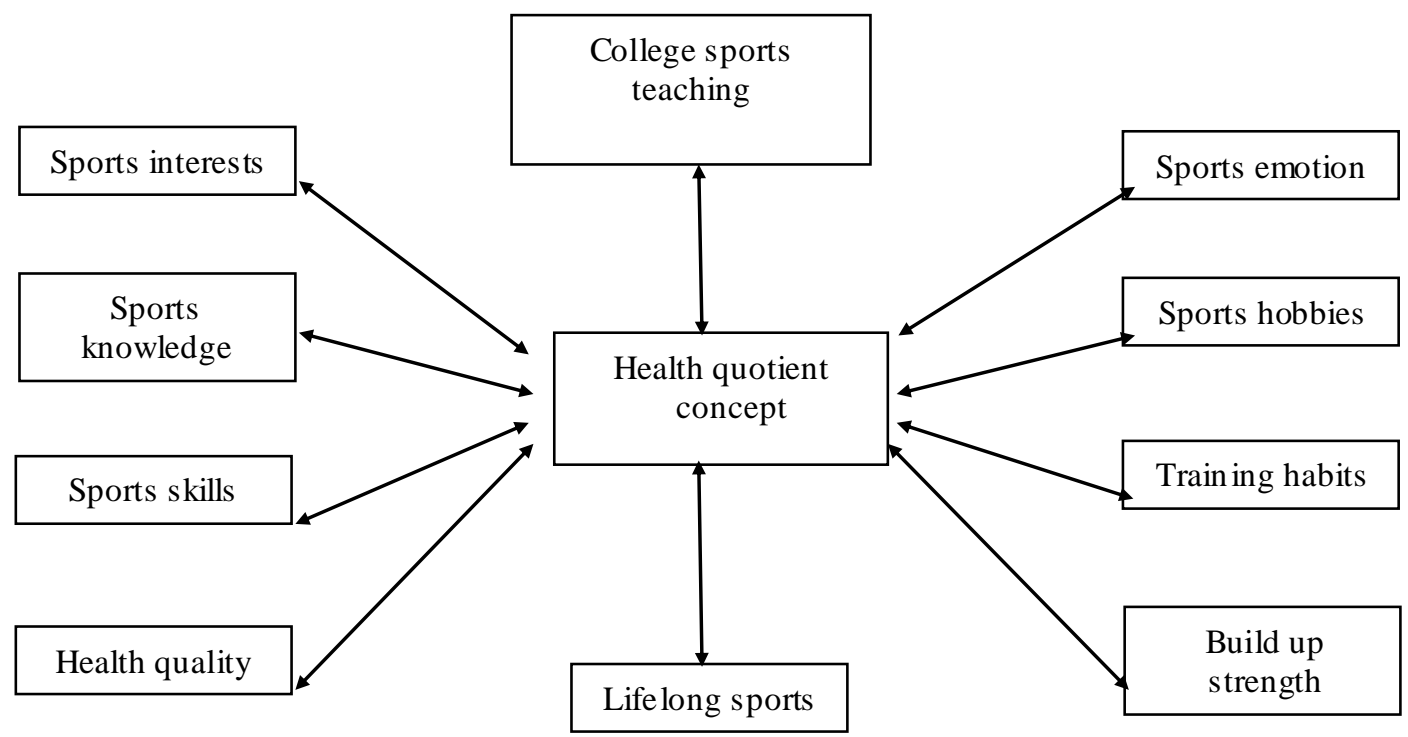

Picture 1 The design picture of the application of the health quotient concept in college

\section{Innovate College Sports' Traditional Teaching Conception}

With the idea of quality education and life-long sports concept implemented in higher education, we need innovate the traditional PE teaching idea, get rid of the influence of traditional teaching thought, carry out more targeted teaching activities and pay attention to the education and cultivation of students' physical and mental qualities. Using health quotient concept in college physical education, physical education teachers can treat it as a guide, impart HQ knowledge in the choice of teaching content, design of teaching process, teaching evaluation and other links correspondingly, cultivate students' health quotient spirit, put sports and health education in a more important position, realize the change from competitive sports in traditional physical education to health education and HQ sport in modern physical education help the students form the habit of sports consciousness and behavior, change teachers and student's physical thinking and promote continuous improvement of the college physical education teaching quality.

\section{Speed up the Construction and Adjustment of College Sports Curriculum System}

With the deepening the reform of college physical education, physical education curriculum system is in the continuous adjustment and optimization. This has a close relationship with construction of sports, the formation of knowledge structure of college students' sports idea and lifelong sports concept formation. College Students' health quotient level is different with IQ, EQ, which is mainly affected by acquired factors. Low defects of contemporary college students' health quotient level is largely attributed to the traditional sports teaching mode and curriculum system. Therefore, using the health quotient philosophy as a guide, making university sports curriculum adjustment system is a general trend. Physical education teachers in colleges should be based on full understanding of health concept, combine health quotient concept with the introduction of the physical education curriculum system construction sufficiently, increase the health quotient teaching curriculum, implement and improve 
the effective supplement of the current curriculum system. On the one hand, this can improve the students in physical education health quotient structure of knowled ge, on the other hand can make the university sports curriculum to better meet the needs of modern sports teaching. For example, in the construction of college PE course, teachers can be targeted to increase health education, sports ethics, interest cultivation course content and select students who love to see and hear the form of teaching. If they can achieve this, it obviously helps students' health quality improvement and quality education.

\section{Improve the Scientifical-ness of Teaching Methods and the Way to Deliver Courses}

In the traditional mode of physical education, the teaching methods are too single, the teaching mode is relatively backward and the teacher's teaching means are too limited, so influence the improvement of teaching quality to a large extent. Therefore, under the guidance of the HQ concept, college physical education teachers should innovate the teaching mode and make some supplement and the consummation to single teaching methods. First of all, teachers should pay attention to the game teaching and the application of happy teaching method, use the rich infective language, create a harmonious, relaxed physical classroom atmosphere for students, strengthen the cultivation of students' interest in sports and exercise the body inner driving force and ensure the initiative of the students in physical education class. Secondly, under the guidance of the HQ concept, teachers should give students more free space and initiative in the PE class. Thirdly, through the variety of teaching methods, teachers should improve the PE class interest and give students more sport confidence and courage, for example, in football theory teaching, teachers can make use of multimedia teaching means to do some complex football action decomposition demonstration and explanation. Or with the aid of the world cup classics of football tactics to explain, it can not only let the PE class in universities become more rich and colorful, but also help improve students' health quality and sports ability.

\section{Establishing the Teaching Evaluation Mechanis m to HQ Idea}

Due to the impact of many traditional factors, teaching evaluation in college sports is mainly take consequential teaching evaluation means and the examination focuses on students' motor skills, making it difficult do targeted evaluation for the student's sports attitude, sports emotion and learning process, which is not conducive for students to form health quotient and lifelong sports concept. Therefore, under the guidance of HQ concept in order to further improve the college sports teaching appraisal work pertinently and scientifically, it is necessary to increase the examination of students' sports emotion, interest in sports, exercise habits, psychological quality and other aspects, realize the effective complement to traditional teaching evaluation system and make a comprehensive, objective, justice evaluation of students' learning process. At the same time, under the guidance of health quotient concept, teachers should realize the diversification of teaching evaluation subject, effectively combine evaluation of teachers, student self-evaluation and mutual evaluation, so that it can enhance students' personal subjective consciousness, shorten the distance in the learning and sports process in the psychological sense and obtain more learning implications and achievements. 


\section{Improve the Health Quality of College Physical Education Teacher}

The effective implementation of health quotient concept in college physical education class depends on the teachers' comprehensive quality and ability to a very great degree. Because teachers are the disseminators of health quotient culture and philosophy, also the influencers of health quotient concept. They play a guiding an important role in disseminating health quotient culture and carrying out health quotient educational activities. Only the physical education teachers in colleges have a corresponding health consciousness and understand how to strengthen the guidance of the health quotient theory can all kinds of health quotient education measures be implemented in the concrete teaching practice and cultivate more students with higher level of health. Therefore, improving the health quality of college physical education teacher is the basis and prerequisite for the implementation of health quotient in sports teaching. Teachers must accept the specialized health quotient education first, pay attention to improve their own health knowledge system, realize the change from the "coach" teachers to "scholars" and constantly improve the level of knowledge and physical quality of their own.

\section{Conclusions}

For college physical education workers, they need to accurately understand the connotation of health quotient, introduce and apply the health quotient concept into the teaching practice of college physical education, then to promote the further development of the College Physical Education in china.

\section{Acknowledgme nts}

This paper for the national social science fund project "the study of urban and rural public sports service equalization demonstration area in the south of Jiangsu construction of one of the achievements. Item number: 14BTY105.

\section{References}

[1] Tong MeiMei. Using the teaching of college physical education to promote modern college students mental health [J].Sports World (Academic Edition), 2011, (01):11-13.

[2] Wang XiaoMei, Li JunHan. A brief analysis of college physical education teaching reform under health education concept [J]. Journal of Southwestern Normal University (NATURAL SCIENCE EDITION), 2008, (04):55-57.

[3]Wang JingYing. Study on the significance and measures to foster the students "Health Quotient" in PE Teaching in Colleges [J]. Journal of Jilin Institute of Physical Education, 2010, (06):35-37.

[4]Liu DeHua. The sociological significance of college sports developing HQ Culture [J]. Journal of Shanxi Normal University Sports Institute, 2006, (02):56-58. 